\title{
Das europäische Umweltmanagementsystem EMAS als Element gesellschaftlicher Selbstregulierung
}

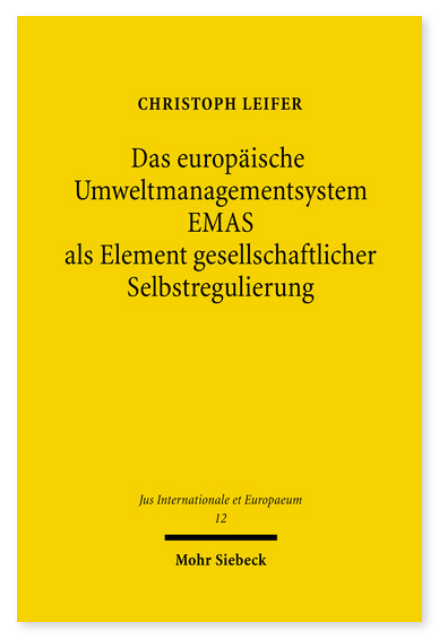

2007. XII, 209 Seiten. JusIntEu 12

ISBN 978-3-16-151151-6

DOI 10.1628/978-3-16-151151-6

eBook PDF $64,00 €$

ISBN 978-3-16-149221-1

fadengeheftete Broschur $64,00 €$
Seit seiner Einführung im Jahr 1993 wurde das europäische Gemeinschaftssystem für das Umweltmanagement und die Umweltbetriebsprüfung (EMAS) als ein Schulbeispiel gesellschaftlicher Selbstregulierungssysteme genannt. Derartige Systeme werden häufig als neue Steuerungsform und sogar als Alternative zu dem gerade aus systemtheoretischer und umweltökonomischer Sicht in die Kritik geratenen Umweltordnungsrecht propagiert. Insbesondere die mangelnde Verbreitung der EMAS-Zertifizierung zeigt jedoch, dass es bei der Diskussion über ordnungsrechtlich-staatliche Instrumente der Umweltpolitik einerseits und Formen der gesellschaftlichen Selbstregulierung andererseits keineswegs um alternative, sondern vielmehr um kumulative Lösungen gehen muss, die insbesondere die Frage nach dem richtigen Verhältnis und der Verschränkung beider Teile aufwirft. Christoph Leifer geht dieser Frage im Fall des europäischen Umweltmanagementsystems EMAS nach und prüft, ob hierbei einerseits die Vorteile gesellschaftlicher Selbstregulierungssysteme genutzt werden, ohne andererseits die staatlichen Schutzpflichten und privaten Grundrechtspositionen außer acht zu lassen, um so zu einer Effizienz des Gesamtsystems zu gelangen. Anschließend untersucht er, wie das System der Selbstregulierung in Form der EMAS-Zertifizierung im Gesamtgefüge der Wirtschafts- und Umweltrechtsordnung verankert ist und welche Auswirkungen diese im Rahmen des Jahresabschlusses, bei der Vergabe öffentlicher Aufträge und bei der Risikoeinschätzung auf Grund umwelthaftungsrechtlicher Bestimmungen sowie deren Versicherbarkeit hat.

Christoph Leifer Geboren 1975; Studium der Rechtswissenschaften in Göttingen; 2006 Promotion; Rechtsanwalt und Lehrbeauftragter an der Fachhochschule Nordhausen; seit 2007 Referent im Ministerbüro des Ministeriums für Umwelt und Naturschutz, Landwirtschaft und Verbraucherschutz des Landes Nordrhein-Westfalen.
Jetzt bestellen:

https://mohrsiebeck.com/buch/das-europaeische-umweltmanagementsystem-emas-als-element-gesellschaftlicherselbstregulierung-9783161511516?no_cache=1

order@mohrsiebeck.com

Telefon: +49 (0)7071-923-17

Telefax: $+49(0) 7071-51104$ 